\title{
Screening of food supplements for toxic pyrrolizidine alkaloids
}

\author{
Florian Kaltner $^{1}\left[\right.$ Verena Kukula $^{1} \cdot$ Christoph Gottschalk ${ }^{1}$ (])
}

Received: 4 June 2020 / Revised: 16 July 2020 / Accepted: 23 July 2020 / Published online: 5 August 2020

(c) The Author(s) 2020

\begin{abstract}
Pyrrolizidine alkaloids (PA) and PA- $N$-oxides (PANO) are a group of more than 660 secondary plant metabolites with hepatotoxic, carcinogenic and mutagenic effects in animals and humans. The phytotoxins can enter the food chain by transfer of PA/PANO between plants via the soil, unintended co-harvesting of PA/PANO-producing weeds, as well as by honeybees collecting pollen and nectar of these plants. Thus, bee- and plant-based products, e.g. (herbal) teas, spices and culinary herbs were identified to be a main source of consumers' exposure to PA/PANO. Consequently, food supplements based on those ingredients may as well be contaminated with PA/PANO, but so far there are only very few studies available on this topic. Therefore, the current study investigated 50 herbal and bee product-based food supplements available in German retail pharmacies, drugstores, and online on the occurrence of 44 PA/PANO. In total, 19 samples contained PA/PANO with sum contents ranging from 0.1 to $105.1 \mathrm{ng} / \mathrm{g}$ in solid samples and from 0.03 to $2.20 \mathrm{ng} / \mathrm{mL}$ in liquid preparations. Considering the recommended daily consumption, the sum contents were of no or little concern for the health risk of adults, whereas in case of children the contents of singular samples could significantly contribute to the overall PA/PANO exposure.
\end{abstract}

Keywords Pyrrolizidine alkaloids $\cdot$ Food safety $\cdot$ Food supplements $\cdot$ Natural products $\cdot$ Preventive health care

\section{Introduction}

Pyrrolizidine alkaloids (PA) and PA- $N$-oxides (PANO) are a group of more than 660 secondary plant metabolites occurring in more than 6000 plant species worldwide. The main producers are plants of the families Asteraceae (Senecioneae, Eupatorieae), Apocynaceae (Echiteae), Boraginaceae, and Fabaceae (genus Crotalaria) (Boppré 2011; Mattocks 1986; Smith and Culvenor 1981). PA/PANO consist of a 1-hydroxymethyl-7-hydroxypyrrolizidine core structure (necine base) esterified to one or two necic acid side chains (Fig. 1). According to their chemical structure, PA/PANO can be further sub-grouped in monoesters, diesters, or cyclic diesters. While cyclic diesters are typically formed by the genera Senecio (Asteraceae), monoesters and open-chained diesters can predominantly be found in genera of Boraginaceae (Hartmann and Witte 1995).

Florian Kaltner

florian.kaltner@1mu.de

1 Chair of Food Safety, Faculty of Veterinary Medicine, Ludwig-Maximilian University of Munich, Schoenleutnerstr. 8, 85764 Oberschleissheim, Germany
Only the 1,2-dehydro-PA/PANO show toxic activities in wildlife, cattle and humans. After intake they can be metabolised to highly reactive pyrrolic esters, which can build adducts with DNA or cellular proteins (Fu et al. 2004). In the past years and decades, several cases of PA/PANO poisonings in humans and animals were reported worldwide (Anjos et al. 2010; Chauvin et al. 1994; Colegate et al. 2012; Kakar et al. 2010). The long-term intake of low PA/PANO doses is associated with chronic diseases such as (liver) cancer, liver cirrhosis, hepatic sinusoidal obstruction syndrome (previously termed as veno-occlusive disease) or pulmonary arterial hypertension (Edgar et al. 2011, 2015; Neuman et al. 2015).

Regulatory limits in food and feedstuffs have not yet been implemented in European law, but are currently under discussion regarding an implementation in Commission Regulation (EC) No. 1881/2006 (Stakeholder Update 2019). Until now, only a maximum content of $100 \mathrm{mg} / \mathrm{kg}$ of PA/PANOcontaining Crotalaria spp. for animal feed materials and compound feed was set in Directive 2002/32/EC (2002). To assess the health risk related to a PA/PANO exposure, the European Food Safety Authority (EFSA) refers to the margin of exposure (MOE) approach (EFSA 2017). In terms of PA/ PANO, a Benchmark Dose Lower Confidence Limit 10\% 
Fig. 1 Chemical core structure of PA and exemplary overview of the different PANO types depending on the grade of esterification

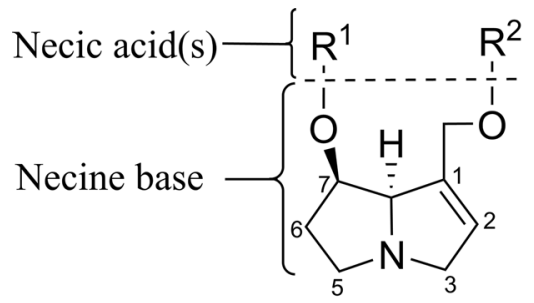

Retronecine-type

Core structure<smiles>C/C=C(/C)C(=O)O[C@H]1CC[N+]2([O-])CC=C(COC(=O)[C@@](O)(C(C)O)C(C)(C)O)[C@H]12</smiles>

Echimidine- $N$-oxide Open-chained diester<smiles>CC(C)[C@](O)(C(=O)OCC1=CCN2CC[C@H](O)[C@H]12)C(C)O</smiles>

Intermedine Monoester<smiles></smiles>

Senecionine Cyclic diester
$\left(\mathrm{BMDL}_{10}\right)$ of $237 \mu \mathrm{g} / \mathrm{kg}$ body weight (BW)/day as toxicological reference point was considered, based on a toxicity study with riddelliine in male and female rats (NTP 2003).

Due to their worldwide occurrence in flowering plants, PA/PANO can contaminate a wide range of food and feed via unintended co-harvesting of PA/PANO-containing plants or via soil transfer (Selmar et al. 2019a, b). If pollen and, in particular, nectar of PA/PANO-containing plants are collected from honeybees, honey and bee product-based products can also be contaminated (Edgar et al. 2002; Lucchetti et al. 2016). In consequence, honey, (herbal) teas, spices and culinary herbs as well as food supplements on the basis of these products were identified by EFSA and the German Federal Institute for Risk Assessment (BfR) to be relevant sources of PA/PANO exposure of consumers (BfR 2016; EFSA 2017).

Food supplements are nowadays of great commercial importance. Revenues of these products in Germany increased from 1.31 bn $€$ in 2017 to 1.44 bn $€$ in 2018 (Food Federation Germany 2020). Besides preparations consisting of concentrated minerals or vitamins, supplements on the basis of herbs or plants are also of common interest. Those food supplements can contain compounds with possible health benefits, but also potential harmful ingredients of concern: In the past, single herbal food supplements samples showed very high PA/PANO amounts (BfR 2016; Mulder et al. 2015). Thus, this food commodity was assumed to greatly contribute to the overall PA/ PANO exposure of consumers. In consequence, the EFSA also recommended to further monitor the occurrence of PA/PANO in relevant food supplements (EFSA 2016). The current study aimed to give a small overview on the occurrence of toxic PA/ PANO in some herbal and bee product-based food supplements available in German retail shops and online.

\section{Materials and methods}

\subsection{Chemical reagents and standards}

Reference standards of 29 PA/PANO were obtained from PhytoLab (Vestenbergsgreuth, Germany). Further 15 standards were purchased from CfM Oskar Tropitzsch (Marktredwitz, Germany). Exact information on the preparation of stock solutions $(\mathrm{c}=1.0 \mathrm{mg} / \mathrm{mL})$ and of the standard mix solution ( $c=1.0 \mu \mathrm{g} / \mathrm{mL}$ for each analyte) is given in Kaltner et al. (2019). Acetonitrile and methanol (both LC-MS-grade) were purchased from Th.Geyer (Renningen, Germany) and used for all experiments. Ultrapure water was obtained by purifying deionised water with an UltraClear ${ }^{\mathrm{TM}}$ system from Evoqua Water Technologies (Barsbuettel, Germany). Sulfuric acid $(0.05 \mathrm{~mol} / \mathrm{L})$ was purchased from Carl Roth (Karlsruhe, Germany) and ammonia solution (25\%) was acquired from Merck (Darmstadt, Germany). Formic acid and ammonium formate were obtained from Th.Geyer (Renningen, Germany) or Fluka (Steinheim, Germany), respectively. 


\subsection{Samples}

In total, 50 food supplement samples were purchased in June and July 2018 (Table 1). Exclusive selection criterion of the samples was their origin, based on plants/herbs (47 samples) or honey (three samples). The sample set consisted of prescription-free food supplements, randomly purchased in pharmacies, drugstores, online shops and supermarkets, including the following dosage forms: pills, coarse and fine powders, juices, syrups and capsules with oily content. Possible applications of the samples ranged from vitamin supply to improved digestion or muscle gain.

\subsection{Sample preparation}

In general, samples in tablet form were pulverised using pestle and mortar, capsuled samples were opened and homogenised, and juices or syrups were lyophilised prior to analysis. Whole stevia leaves (sample no. 50) were ground and homogenised to a particle size $<1 \mathrm{~mm}$ using a ZM 200 centrifugal mill from Retsch (Haan, Germany). In case of dry samples, $2.0 \mathrm{~g}$ of sample material were extracted with $40 \mathrm{~mL}$ aqueous sulphuric acid $(0.05 \mathrm{~mol} / \mathrm{L}) .25 \mathrm{~mL}$ of juice or syrup samples were lyophilised and afterwards reconstituted with $40 \mathrm{~mL}$ aqueous sulphuric acid $(0.05 \mathrm{~mol} / \mathrm{L})$. The further sample preparation procedure was performed as published previously (Kaltner et al. 2019). In case of samples with oily capsule content (samples no. 24, 36, 38, 44) or water-binding appetite suppressant capsules (sample no. 1), extraction of $2.0 \mathrm{~g}$ sample was performed with $20 \mathrm{~mL}$ of methanolic sulphuric acid $(0.05 \mathrm{~mol} / \mathrm{L})$. Subsequently, in these cases the SPE cartridges were conditioned with $5 \mathrm{~mL}$ methanolic sulphuric acid $(0.05 \mathrm{~mol} / \mathrm{L})$ instead of $5 \mathrm{~mL}$ of aqueous sulphuric acid $(0.05 \mathrm{~mol} / \mathrm{L})$.

\subsection{Analytical conditions and quantification of PA/ PANO}

Exact analytical conditions of the liquid chromatography tandem mass spectrometry (LC-MS/MS) system, the multiple reaction monitoring (MRM) transitions of the $[\mathrm{M}+\mathrm{H}]^{+}$ ions of the analytes as well as their retention times can

Table 1 Types, dosage forms and origins of food supplement samples investigated in the current study

\begin{tabular}{|c|c|c|c|c|c|c|c|}
\hline No. & Description & Dosage form & Place of purchase & No. & Description & Dosage form & Place of purchase \\
\hline 1 & Slim satiating capsules & Capsule & Drugstore & 26 & Protein shake powder & Powder & Internet trade \\
\hline 2 & Body change green powder & Powder & Drugstore & 27 & Pea protein powder & Powder & Internet trade \\
\hline 3 & Rampion-rosehip capsules & Capsule & Drugstore & 28 & Red clover capsules & Capsule & Internet trade \\
\hline 4 & Whitethorn dragées & Capsule & Drugstore & 29 & Green tea capsules & Capsule & Internet trade \\
\hline 5 & Vegan superfood blend & Powder & Internet trade & 30 & Artichoke capsules & Capsule & Health food store \\
\hline 6 & Superfood blend for women & Powder & Internet trade & 31 & Wheatgrass powder & Powder & Internet trade \\
\hline 7 & Vegan protein drink & Powder & Internet trade & 32 & Camu Camu capsules & Capsule & Internet trade \\
\hline 8 & Vitamin B12 tablets & Pill & Internet trade & 33 & Barley grass powder & Powder & Internet trade \\
\hline 9 & Royal jelly capsules & Capsule & Drugstore & 34 & Moringa powder & Powder & Internet trade \\
\hline 10 & Propolis syrup & Syrup/juice & Drugstore & 35 & Nettle and herb tablets & Pill & Internet trade \\
\hline 11 & Manuka honey syrup & Syrup/juice & Drugstore & 36 & Capsules with St. John's wort & Capsule & Internet trade \\
\hline 12 & Iron-vitamin B12 dragées & Syrup/juice & Pharmacy & 37 & Herbal pills with valerian & Pill & Internet trade \\
\hline 13 & Sports-iron syrup & Syrup/juice & Pharmacy & 38 & Capsules with milk thistle & Capsule & Internet trade \\
\hline 14 & Iron-folic acid dragées & Capsule & Pharmacy & 39 & Artichoke capsules & Capsule & Internet trade \\
\hline 15 & $\begin{array}{l}\text { Aronia juice with zinc and } \\
\text { selenium }\end{array}$ & Syrup/juice & Pharmacy & 40 & Herbadigestive tablets & Pill & Internet trade \\
\hline 16 & Syrup preparation with iron & Syrup/juice & Pharmacy & 41 & Bile-artichoke dragées & Capsule & Internet trade \\
\hline 17 & Vitamin C pellet & Pellet & Pharmacy & 42 & Skin/hair/nails pellets & Pellet & Internet trade \\
\hline 18 & Rosehip-nettle-rampion juice & Syrup/juice & Pharmacy & 43 & Vitamin preparation & Capsule & Internet trade \\
\hline 19 & Moringa powder & Powder & Internet trade & 44 & Vitamin capsules for women & Capsule & Internet trade \\
\hline 20 & Maca and hemp protein & Powder & Internet trade & 45 & Stevia leaf powder & Powder & Health food store \\
\hline 21 & Smoothie balls & Pellet & Internet trade & 46 & Stevia leaf powder & Powder & Internet trade \\
\hline 22 & Vegan protein & Powder & Internet trade & 47 & Inner peace/relax pellets & Pellet & Internet trade \\
\hline 23 & Pukka green powder & Powder & Health food store & 48 & Juice concentrate & Syrup/juice & Internet trade \\
\hline 24 & $\begin{array}{l}\text { Milk-plus capsules for lactating } \\
\text { women }\end{array}$ & Capsule & Health food store & 49 & Body balance preparation & Capsule & Health food store \\
\hline 25 & Veggie pellets & Pellet & Internet trade & 50 & Stevia leaves & Leaves & Internet trade \\
\hline
\end{tabular}


be found in Kaltner et al. (2019). Samples were initially screened for the presence of $44 \mathrm{PA} / \mathrm{PANO}$. Concentrations of present PA/PANO were determined by standard addition to the final sample extracts to compensate for ion suppressing effects in the MS. Therefore, $10 \mu \mathrm{L}$ aliquots of diluted PA/PANO mix solutions were added to $250 \mu \mathrm{L}$ aliquots of the final sample extracts. Depending on the PA/PANO concentrations estimated from the initial screening runs, the two standard addition levels were slightly modified for each sample. Added levels were $0.2 / 0.4 \mathrm{ng} / \mathrm{mL}, 0.25 / 1.0 \mathrm{ng} / \mathrm{mL}$, $1.0 / 2.0 \mathrm{ng} / \mathrm{mL}$ or $8.2 / 16.4 \mathrm{ng} / \mathrm{mL}$. The concentration of the unspiked sample extracts were defined as " $0 \mathrm{ng} / \mathrm{mL}$ ". The three concentration levels were plotted against the respective peak areas of the analytes and a linear regression line was calculated. The absolute value of the intercept of the $\mathrm{x}$-axis was the concentration of the analyte in the sample.

\section{Results and discussion}

An exemplarily sample set of 50 herbal and bee productbased food supplement samples was analysed for the presence of hepatotoxic PA/PANO. The samples covered a wide range of typical dosage forms of food supplements, including powders, shakes, pills, capsules, pellets, syrups, juices and whole leaves (Table 1). In consequence, nearly every sample had to be treated slightly different concerning weighing, homogenisation and extraction. Within the 50 samples, 19 samples (38\%) contained at least one PA/PANO compound (Table 2). In 15 solid samples, e.g. pills or powders, the detected contents ranged from 0.1 to $105.1 \mathrm{ng} / \mathrm{g}$, whereas in four juices and syrups PA/PANO levels from 0.03 to $2.20 \mathrm{ng} / \mathrm{mL}$ were determined. PA/PANO were found in all dosage forms and in every kind of purchase place of the food supplements.

The samples were screened for an analyte set consisting of $44 \mathrm{PA} / \mathrm{PANO}$, covering alkaloids that can typically be found in the well-known PA/PANO-containing plant families Asteraceae, Boraginacea and Fabaceae (genus Crotalaria). The most abundant analytes detected in the samples were PA/PANO of the lycopsamine-type (intermedine, lycopsamine, and corresponding $N$-oxides) and the heliotrine-type (heliotrine, europine, lasiocarpine and corresponding $N$-oxides). Both PA/PANO-types mainly occur in Boraginaceae plants, typically from the genera such as Heliotropium, Symphytum, Borago or Echium (Hartmann and Witte 1995). Some samples showed contaminations with senecionine-type PA/PANO as dominant analytes, that can be found in the plant genera Senecio of the Asteraceae family. In contrast, no Crotalaria PA/PANO, e.g. monocrotaline or trichodesmine, were found in the samples. Interestingly, higher levels of PA than PANO were found in some preparations. The more hydrophilic PANO are supposed to be the transport metabolite which are required to translocate the alkaloids in the phloem of plants (Nowak and Selmar 2016). Dependant on the respective plants, the PANO are transformed back to tertiary amines when arriving at the sink tissues (e.g. fruits or seeds) in the plants. Thus, the increased levels of detected PA, compared to their corresponding PANO, may indicate a contamination proportion of the respective supplements with seeds or fruits of PA/PANO containing plants compared to other plant parts.

In total, three bee product-based food supplements were investigated, namely royal jelly capsules (no. 9) and two syrups based on propolis (no. 10) or manuka honey (no. 11) as an ingredient. PA/PANO were detected in both syrups, with $2.20 \mathrm{ng} / \mathrm{mL}$ in the propolis syrup and $0.28 \mathrm{ng} / \mathrm{mL}$ in the manuka honey syrup. The low contents were consistent with data published in former studies: Picron et al. reported 17 of $23(74 \%)$ bee product-based food supplements to contain PA/PANO at low levels up to a small maximum content of $43.2 \mathrm{ng} / \mathrm{g}$ and a median content of $0.9 \mathrm{ng} / \mathrm{g}$ (Picron et al. 2020). A study from Mulder et al. reported mean PA/PANO sum levels of $15.5 \mathrm{ng} / \mathrm{g}$ in food supplements based on royal jelly and only $0.6 \mathrm{ng} / \mathrm{g}$ in propolis products (Mulder et al. 2015).

The detected PA/PANO sum levels among the 15 positive solid samples within the remaining 47 herbal-based food supplement samples lay within a range from 0.1 to $105.1 \mathrm{ng} / \mathrm{g}$, with a median of $5.1 \mathrm{ng} / \mathrm{g}$ and a mean content of $20.1 \mathrm{ng} / \mathrm{g}$. Two herbal-based juice samples contained $0.03 \mathrm{ng} / \mathrm{mL}$ or $0.26 \mathrm{ng} / \mathrm{mL}$ (no. 18 and 48 ). Nevertheless, these contents and also the percentage of positive samples in our study (38\%) both were remarkably low compared to previously published studies. An investigated set of 107 plant food supplements not containing known PA/PANOproducing plants resulted in a maximum sum content of $8488 \mathrm{ng} / \mathrm{g}$, with 28 considered analytes, and reported 63\% positive samples (Mulder et al. 2015). Moreover, Letsyo et al. reported a maximum of $3270 \mathrm{ng} / \mathrm{g}$ and 63 positive samples in a set of 98 retail herbal medicines (2017), and in 17 out of 23 samples (74\%) of indonesian herbal medicines ("jamu") produced without PA/PANO-containig plants, PA/PANO sum contents of up to $3421 \mu \mathrm{g} / \mathrm{kg}$ were described (Suparmi et al. 2020). In addition, in case of our sample set, no PA/PANO-producing plants were used as ingredients according to their respective packaging. Indeed, the respective median presented in the study of Mulder et al. (2015) was $11.4 \mathrm{ng} / \mathrm{g}$ and thus comparably low like the median of $5.1 \mathrm{ng} / \mathrm{g}$ calculated in our study. This may be an indicator that, even when no PA/PANOproducing plants are involved, high PA/PANO levels occur only sporadically in herbal food supplements.

However, the low sum levels of PA/PANO reported in our study may be due to increased attention of producers to avoid accidental co-harvesting of plants containing PA/ 
Table 2 Margin of exposure values of samples with at least one PA or PANO at levels above the limit of detection

\begin{tabular}{|c|c|c|c|c|c|c|}
\hline \multirow[t]{2}{*}{ Sample no. } & \multirow{2}{*}{$\begin{array}{l}\text { Botanical origin of pre- } \\
\text { dominant PA/PANO }\end{array}$} & \multirow{2}{*}{$\begin{array}{l}\text { PA/PANO sum } \\
\text { content }[\mathrm{ng} / \mathrm{g}]\end{array}$} & \multirow{2}{*}{$\begin{array}{l}\text { Consumption of food } \\
\text { supplement [g/day] }\end{array}$} & \multirow{2}{*}{$\begin{array}{l}\text { PA/PANO intake } \\
\text { [ng/day] }\end{array}$} & \multicolumn{2}{|c|}{ Margin of exposure ${ }^{a}$} \\
\hline & & & & & Child (16 kg) & Adult $(70 \mathrm{~kg})$ \\
\hline \multicolumn{7}{|l|}{ Solids } \\
\hline 4 & Boraginaceae & 1.5 & 0.4 & 0.6 & $6,320,000$ & $>10,000,000$ \\
\hline 20 & Asteraceae & 0.7 & 20 & 14.0 & 271,000 & $1,119,000$ \\
\hline 21 & Boraginaceae & 0.4 & 25 & 10.0 & 379,000 & $1,660,000$ \\
\hline 28 & Asteraceae & 5.1 & 0.6 & 3.1 & $1,220,000$ & $5,350,000$ \\
\hline 29 & Boraginaceae & 0.1 & 1.2 & 0.1 & $>10,000,000$ & $>10,000,000$ \\
\hline 30 & Boraginaceae & 21.0 & 2.3 & 48.3 & 78,500 & 343,000 \\
\hline 31 & Boraginaceae & 0.3 & 9 & 2.7 & $1,400,000$ & $6,140,000$ \\
\hline 35 & Boraginaceae & 50.1 & 4.0 & 200.4 & 18,900 & 82,800 \\
\hline 36 & Boraginaceae & 1.8 & 0.4 & 0.7 & $5,420,000$ & $>10,000,000$ \\
\hline 38 & Boraginaceae & 3.2 & 0.4 & 1.3 & $2,920,000$ & $>10,000,000$ \\
\hline 40 & Boraginaceae & 105.1 & 2.5 & 262.8 & 14,400 & 63,100 \\
\hline 42 & Boraginaceae & 33.1 & 0.7 & 23.2 & 163,000 & 715,000 \\
\hline 47 & Asteraceae & 36.5 & 1.6 & 58.4 & 64,900 & 284,000 \\
\hline 49 & Boraginaceae & 35.4 & 0.7 & 24.8 & 153,000 & 669,000 \\
\hline 50 & Boraginaceae & 8.6 & 0.2 & 1.7 & $2,230,000$ & $9,760,000$ \\
\hline Liquids & & {$[\mathrm{ng} / \mathrm{mL}]$} & [mL/day] & & & \\
\hline 10 & Boraginaceae & 2.20 & 10 & 22.0 & 172,000 & 754,000 \\
\hline 11 & Boraginaceae & 0.28 & 10 & 2.8 & $1,350,000$ & $5,930,000$ \\
\hline 18 & Boraginaceae & 0.26 & 40 & 10.4 & 365,000 & $1,600,000$ \\
\hline 48 & Boraginaceae & 0.03 & 20 & 0.6 & $6,320,000$ & $>10,000,000$ \\
\hline
\end{tabular}

The botanical origin of the predominant PA/PANO analytes and the PA/PANO sum contents of samples are given. The daily consumption of a food supplement resulted from the recommended intake and, if necessary, the average weight of the capsules or pills

${ }^{a}$ Based on a Benchmark Dose Lower Confidence Limit 10\% (BMDL 10$)$ of $237 \mu \mathrm{g} / \mathrm{kg}$ body weight $/ \mathrm{d}$ for the sum of PA/PANO intake

PANO, potentially induced by the numerous reports on PA/PANO contamination of herbal products during the last years. If the detected low amounts of PA/PANO in the herbal based food supplements may be due to horizontal transfer, the imported alkaloids might be modified, e.g. by hydroxylation or glucosylation, as recently outlined (Selmar et al. 2019a, b). In consequence, additional investigations of (herbal) food supplements via sum-based methods (Cramer et al. 2013) should be included to cover for potentially occurring modified PA/PANO.

Nevertheless, in previous studies singular supplements were already shown to contain extremely high sum contents, in particular when PA/PANO-producing plants were used as ingredients. Herein, Mulder et al. reported in their study up to $2,410,275 \mathrm{ng} / \mathrm{g}$ (i.e. $2.4 \mathrm{mg} / \mathrm{g}$ ) in a set of 18 samples (Mulder et al. 2015), and Suparmi et al. reported levels of up to $235,376 \mathrm{ng} / \mathrm{g}$ in jamu herbal medicine samples made from PA/PANO-containing botanicals (Suparmi et al. 2020). In fact, due to limited number of samples, the current study cannot be seen as fully representative concerning the general occurrence of PA/PANO in food supplements, however highlighting further need of research.

To the best of our knowledge, this is the first time that toxic PA/PANO were identified in whole and dried Stevia leaves intended for direct consumption as sweetener for teas and other beverages (sample no. 50). The detected sum content of $8.6 \mathrm{ng} / \mathrm{g}$ was low and can be seen as minor issue, as due to its potent sweetening power only small amounts of stevia would be used by consumers. Although, this result can be regarded as a first hint to possibly include Stevia products into future PA/PANO monitoring activities. In case of products based on oil from plant seeds, PA/PANO were detected in two samples (no. 36 and 38) at sum levels of $1.8 \mathrm{ng} / \mathrm{g}$ or $3.2 \mathrm{ng} / \mathrm{g}$, respectively. Although the contents were quite low, the results were contrary to the study of Mulder et al. were no PA/PANO were determined above the limit of detection in a set of 24 oil-based food supplements (Mulder et al. 2015).

The obtained results on the occurrence of PA/PANO in the investigated food supplements were used to assess the health risk for children and adult consumers due to a 
chronic intake. Therefore, the MOE approach was used, based on a BMDL ${ }_{10}$ of $237 \mu \mathrm{g} / \mathrm{kg} \mathrm{BW} /$ day. In general, MOE values $>10,000$ are regarded as being of little concern for risk management, while MOE values $<10,000$ indicate a potential health risk for consumers. In contrast to a usual risk assessment, different intake scenarios were not taken into account. Instead, the intake recommendations of the food supplements were considered. According to the German Food Supplements Regulation (NemV 2004), to avoid overdosages, the products have additionally to be labelled with a warning not to exceed the recommended daily intake.

In case of adults, the performed risk assessment revealed MOE values from 63,100 to more than $10,000,000$ (Table 2), which turned out to be unproblematic concerning consumers' health. Even when ingested by the sensitive subpopulation of children, most of the food supplements resulted in harmless MOE values, with only two samples leading to MOEs slightly higher than 10,000 (no. 35 and 40). Nevertheless, for a proper risk assessment every potential source of exposure must be considered. Thus, the combined intake of several putatively unproblematic amounts of PA/PANO via different sources, e.g. honey, (herbal) teas or spices, cereals, meat, or milk (EFSA 2016), may easily lead to critical MOE values. In consequence, food supplements may significantly contribute to the overall exposure if consumed in combination with common foodstuffs. Therefore, PA/PANO in herbal and bee product-based food supplements remain a possible health risk to consumers and thus, these contaminants should further be monitored thoroughly. The presence of toxic and carcinogenic contaminants in food generally should be avoided (Council Regulation (EEC) No. 315/93 1993). This should in particular be the case for products such as food supplements which are used with the intention of providing a health benefit.

Within our sample set, no known PA/PANO containing ingredients were used. In the past, very high PA/ PANO levels were found in singular herbal food supplements where PA/PANO-containing plants were used as ingredients (BfR 2016). Thus, the daily intake of PA/ PANO by consumers of food supplements, in particular for children, can be excessive. Due to their potential health risk, food supplement preparations consisting of known PA/PANO-producing plants should generally be avoided (BfR 2016). Besides PA/PANO, (herbal) food supplements have recently been identified also to possibly contain other genotoxic and carcinogenic compounds, e.g. aristolochic acids or alkylbenzenes (Prinsloo et al. 2019) or mycotoxins (Gottschalk et al. 2016). In general, the use of food supplements should be considered with care as concerns on their safety and quality are known, including chemical and microbiological contamination (EFSA 2009).

\section{Conclusions}

In the current study, a sample set of 50 herbal and bee product-based food supplements from German retail stores, pharmacies and internet trade was investigated on the occurrence of hepatotoxic PA/PANO. While 31 samples (62\%) were free of PA/PANO, 19 samples (38\%) contained PA/PANO up to a comparably low maximum PA/PANO sum content of $105.1 \mathrm{ng} / \mathrm{g}$. The MOE evaluation for assessing the chronic health risk revealed no health risk for adults. Nevertheless, singular supplements within the sample set may raise a potential health risk to children and markedly contributed to the all-over PA/PANO intake via other sources (e.g. tea, honey). Although our study showed only MOE values $>10,000$, food supplements should not be neglected as potential source of PA/PANO exposure. Thus, these products should be further monitored regarding a presence of toxic PA/PANO.

Acknowledgements Open Access funding provided by Projekt DEAL.

Author contributions Conceptualisation, FK; investigation, VK; writing - original draft preparation, VK and FK, writing - review and editing, CG; visualization, FK; supervision, FK; funding acquisition, FK.

Funding The study was financially supported within the VETResearch program of the Veterinary Faculty of the Ludwig-Maximilian University of Munich. This research program was sponsored by the German Federal Ministry of Education and Research (BMBF) (Grant no. 01PL17016). Any opinions expressed here are those of the authors.

Availability of data and material All recorded and processed data are stored at university servers for long-term utilisation. These will be made available to other researchers upon request.

\section{Compliance with ethical standards}

Conflict of interest The authors declare that they have no conflict of interest.

Open Access This article is licensed under a Creative Commons Attribution 4.0 International License, which permits use, sharing, adaptation, distribution and reproduction in any medium or format, as long as you give appropriate credit to the original author(s) and the source, provide a link to the Creative Commons licence, and indicate if changes were made. The images or other third party material in this article are included in the article's Creative Commons licence, unless indicated otherwise in a credit line to the material. If material is not included in the article's Creative Commons licence and your intended use is not permitted by statutory regulation or exceeds the permitted use, you will need to obtain permission directly from the copyright holder. To view a copy of this licence, visit http://creativecommons.org/licenses/by/4.0/.

\section{References}

Anjos BL, Nobre VMT, Dantas AFM, Medeiros RMT, Oliveira Neto TS, Molyneux RJ, Riet-Correa F (2010) Poisoning of sheep by seeds of Crotalaria retusa: acquired resistance by continuous 
administration of low doses. Toxicon 55:28-32. https://doi. org/10.1016/j.toxicon.2009.06.028

BfR (2016) Opinion No. 030/2016: Pyrrolizidine alkaloids: levels in foods should continue to be kept as low as possible. Federal Institute for Risk Assessment, Berlin

Boppré M (2011) The ecological context of pyrrolizidine alkaloids in food, feed and forage: an overview. Food Addit Contam Part A 28:260-281. https://doi.org/10.1080/19440049.2011.555085

Chauvin P, Dillon JC, Moren A (1994) An outbreak of Heliotrope food poisoning, Tadjikistan, November 1992-March 1993. Sante (Montrouge, France) 4:263-268

Colegate SM, Stegelmeier BL, Edgar JA (2012) Dietary exposure of livestock and humans to hepatotoxic natural products. Animal feed contamination: effects on livestock and food safety. Elsevier, Amsterdam, pp 352-382. https://doi.org/10.1533/97808 57093615.3.352

Council Regulation (EEC) No. 315/93 (1993) Laying down community procedures for contaminants in food. Off $\mathrm{J}$ Eur Communities Law 37:1-3

Cramer L, Schiebel HM, Ernst L, Beuerle T (2013) Pyrrolizidine alkaloids in the food chain: development, validation, and application of a new HPLC-ESI-MS/MS sum parameter method. J Agric Food Chem 61:11382-11391. https://doi.org/10.1021/jf403647u

Directive 2002/32/EC of the European Parliament and of the Council (2002) On undesirable substances in animal feed. Off J Eur Communities Law 140:10-22

Edgar JA, Roeder E, Molyneux RJ (2002) Honey from plants containing pyrrolizidine alkaloids: a potential threat to health. J Agric Food Chem 50:2719-2730. https://doi.org/10.1021/jf0114482

Edgar JA, Colegate SM, Boppré M, Molyneux RJ (2011) Pyrrolizidine alkaloids in food: a spectrum of potential health consequences. Food Addit Contam Part A 28:308-324. https://doi. org/10.1080/19440049.2010.547520

Edgar JA, Molyneux RJ, Colegate SM (2015) Pyrrolizidine alkaloids: potential role in the etiology of cancers, pulmonary hypertension, congenital anomalies, and liver disease. Chem Res Toxicol 28:4-20. https://doi.org/10.1021/tx500403t

EFSA (2009) Guidance on safety assessment of botanicals and botanical preparations intended for use as ingredients in food supplements. EFSA J. https://doi.org/10.2093/j.efsa.2009.1249

EFSA (2016) Dietary exposure assessment to pyrrolizidine alkaloids in the European population. EFSA J. https://doi.org/10.2903/j. efsa.2016.4572

EFSA (2017) Risks for human health related to the presence of pyrrolizidine alkaloids in honey, tea, herbal infusions and food supplements. EFSA J. https://doi.org/10.2903/j.efsa.2017.4908

Food Federation Germany (2020) Deutscher Lebensmittelverband. https://www.lebensmittelverband.de/de/verband/organisation/ arbeitskreis-nahrungsergaenzungsmittel-ak-nem/20181029zahlen-nahrungsergaenzungsmittel-markt-2018. Accessed 17 Apr 2020

Fu PP, Xia Q, Lin G, Chou MW (2004) Pyrrolizidine alkaloidsgenotoxicity, metabolism enzymes, metabolic activation, and mechanisms. Drug Metab Rev 36:1-55. https://doi.org/10.1081/ DMR-120028426

Gottschalk C, Biermaier B, Gross M, Schwaiger K, Gareis M (2016) Ochratoxin A in brewer's yeast used as food supplement. Mycotoxin Res 32:1-5. https://doi.org/10.1007/s12550-015-0230-x

Hartmann T, Witte L (1995) Chemistry, biology and chemoecology of the pyrrolizidine alkaloids. In: Pelletier SW (ed) Alkaloids: chemical and biological perspectives. Elsevier, Amsterdam, pp $155-233$

Kakar F et al (2010) An outbreak of hepatic veno-occlusive disease in Western Afghanistan associated with exposure to wheat flour contaminated with pyrrolizidine alkaloids. J Toxicol. https://doi. org/10.1155/2010/313280
Kaltner F, Stiglbauer B, Rychlik M, Gareis M, Gottschalk C (2019) Development of a sensitive analytical method for determining 44 pyrrolizidine alkaloids in teas and herbal teas via LC-ESI-MS/ MS. Anal Bioanal Chem 411:7233-7249. https://doi.org/10.1007/ s00216-019-02117-1

Letsyo E, Jerz G, Winterhalter P, Lindigkeit R, Beuerle T (2017) Incidence of pyrrolizidine alkaloids in herbal medicines from German retail markets: risk assessment and implications to consumers. Phytother Res 31:1903-1909. https://doi.org/10.1002/ptr.5935

Lucchetti MA, Glauser G, Kilchenmann V, Dubecke A, Beckh G, Praz C, Kast C (2016) Pyrrolizidine alkaloids from Echium vulgare in honey originate primarily from floral nectar. J Agric Food Chem 64:5267-5273. https://doi.org/10.1021/acs.jafc.6b02320

Mattocks AR (1986) Chemistry and toxicology of pyrrolizidine alkaloids. Academic Press, London

Mulder PPJ, López Sánchez P, These A, Preiss-Weigert A, Castelari M (2015) Occurrence of pyrrolizidine alkaloids in food. EFSA Supporting Publication, Parma, p 116

NemV (2004) (German Food Supplements Regulation); Nahrungsergänzungsmittelverordnung vom 24. Mai 2004 (BGBl. I S. 1011), die zuletzt durch Artikel 11 der Verordnung vom 5. Juli 2017 (BGB1. I S. 2272) geändert worden ist

Neuman MG, Cohen LB, Opris M, Nanau R, Jeong H (2015) Hepatotoxicity of pyrrolizidine alkaloids. J Pharm Pharm Sci 18:825843. https://doi.org/10.18433/J3BG7J

Nowak M, Selmar D (2016) Cellular distribution of alkaloids and their translocation via phloem and xylem: the importance of compartiment pH. Plant Biol 18:879-882. https://doi.org/10.1111/ plb.12504

NTP (National Toxicology Program) (2003) Toxicology and carcinogenesis studies of riddelliine. National Toxicology Program Technical Report 508

Picron JF, Herman M, Van Hoeck E, Goscinny S (2020) Monitoring of pyrrolizidine alkaloids in beehive products and derivatives on the Belgian market. Environ Sci Pollut Res 27:5693-5708. https ://doi.org/10.1007/s11356-019-04499-2

Prinsloo G, Steffens F, Vervoort J, Rietjens IM (2019) Risk assessment of herbal supplements containing ingredients that are genotoxic and carcinogenic. Crit Rev Toxicol 49:567-579. https://doi. org/10.1080/10408444.2019.1686456

Selmar D, Radwan A, Hijazin T, Abouzeid S, Yahyazadeh M, Lewerenz L, Kleinwächter M, Nowak M (2019a) Horizontal natural product transfer: intriguing insights into a newly discovered phenomenon. J Agric Food Chem 67:8740-8745. https://doi. org/10.1021/acs.jafc.9b03619

Selmar D, Wittke C, Beck-von Wolffersdorff I, Klier B, Lewerenz L, Kleinwächter M, Nowak M (2019b) Transfer of pyrrolizidine alkaloids between living plants: a disregarded source of contaminations. Environ Pollut 248:456-461. https://doi.org/10.1016/j. envpol.2019.02.026

Smith LW, Culvenor CCJ (1981) Plant sources of hepatotoxic pyrrolizidine alkaloids. J Nat Prod 44:129-152. https://doi. org/10.1021/np50014a001

Stakeholder Update 2019 on Rapidly Developing Policy on Food Contaminants (2019) Food Standards Agency. https://www.food.gov. uk/news-alerts/consultations/june-2019-stakeholder-update-onrapidly-developing-policy-on-food-contaminants. Accessed 29 Sept 2019

Suparmi S, Mulder PPJ, Rietjens I (2020) Detection of pyrrolizidine alkaloids in jamu available on the Indonesian market and accompanying safety assessments for human consumption. Food Chem Toxicol 138:111230. https://doi.org/10.1016/j.fct.2020.111230

Publisher's Note Springer Nature remains neutral with regard to jurisdictional claims in published maps and institutional affiliations. 